\title{
Experiencing earthquake in the first trimester of the fetal life increases subsequent diabetes risk in the adulthood: a cross-sectional study
}

Na Li, Mei Song, Lan Wang, Xiao-chuan Zhao, Ran Wang, Yuan-yuan Gao, Lu-lu Yu, Cui-xia An* and Xue-yi Wang*

\begin{abstract}
Objective: To investigate the long-term effect of prenatal exposure to earthquake stress on diabetes risk in the adulthood.

Methods: This study included employees of Tangshan Kailuan Mining Group between July 29, 1976 and April 28, 1977. The exposure group included subjects who experienced the Tangshan Earthquake during their prenatal period and who had lived in Tangshan since birth. The non-exposure group included subjects who were born 11.9 years after the earthquake and who had lived in Tangshan since birth. A questionnaire was designed that included sociodemographic information, conditions during pregnancy, and earthquake experience. Anthropometric measurements including height and weight, body mass index (BMI), waist circumference were made. Fasting plasma glucose (FPG) and lipid profiles were also determined.

Results: Totally 947 subjects were included with 397 subjects in the exposed group and 550 subjects in the nonexposed group. The diabetes rate is significant different in these four $\operatorname{groups}\left(x^{2}=8.045, P=0.045\right)$. Moreover, 11.8 , 7.5 and $8.0 \%$ of the subjects who were exposed to earthquake in the 1st, $2 \mathrm{nd}$, and 3rd trimester of pregnancy had diabetes. $5.1 \%$ of the subjects had diabetes in non-exposure group. Our multivariate analysis showed that $1 \mathrm{st}$ trimester $(\mathrm{OR} 2.481,95 \% \mathrm{Cl} 1.02,6.034 ; P=0.045)$ and loss of family members during earthquake $(\mathrm{OR} 2.452,95 \% \mathrm{Cl}$ $1.293,4.653 ; P=0.006)$ were associated with significantly increased risk of diabetes.

Conclusions: Exposure to earthquake during the first trimester of pregnancy and experience of family member loss in the earthquake significantly increased the subsequent risk of diabetes in the middle age (36-39 years of age). Our data suggest that earthquake experience in the early pregnancy has a longer-term effect on diabetes risk during adulthood.
\end{abstract}

Keywords: Prenatal earthquake stress, Middle age, Diabetes mellitus, Risk factors

\footnotetext{
*Correspondence: acxsunny@163.com; ydyywxy@163.com

Department of Psychiatry, the First Hospital of Hebei Medical University, Mental Health Institute of the Hebei Medical University, No.89 Donggang

Road, Yuhua District, Shijiazhuang 050031, Hebei, China
}

(c) The Author(s). 2020 Open Access This article is licensed under a Creative Commons Attribution 4.0 International License, which permits use, sharing, adaptation, distribution and reproduction in any medium or format, as long as you give appropriate credit to the original author(s) and the source, provide a link to the Creative Commons licence, and indicate if changes were made. The images or other third party material in this article are included in the article's Creative Commons licence, unless indicated otherwise in a credit line to the material. If material is not included in the article's Creative Commons licence and your intended use is not permitted by statutory regulation or exceeds the permitted use, you will need to obtain permission directly from the copyright holder. To view a copy of this licence, visit http://creativecommons.org/licenses/by/4.0/ The Creative Commons Public Domain Dedication waiver (http://creativecommons.org/publicdomain/zero/1.0/) applies to the data made available in this article, unless otherwise stated in a credit line to the data. 


\section{Introduction}

The maternal pregnancy (prenatal stage) is an important period for the healthy development of the fetus. However, stressful life events during pregnancy not only impact on the mother and fetal development in utero but also cause long-term adverse outcomes in the offspring born from stress-burdened mothers [1, 2]. Increasing evidence has indicated that the origins of certain agerelated diseases such as diabetes could be traced back to stressful experiences during the fetal period in utero [3]. Stress can change blood flow to the uterus and hence to the fetus, and may cause structural and/or functional alterations in the cell, tissue, and organ system of the fetus. The incidence of diabetes mellitus was reportedly increased by $22 \%$ in children exposed to hurricane during their infancy or prenatal life [4].

During the fetal period, the brain regions that are involved in modulating the hypothalamus-pituitaryadrenal (HPA) axis, such as the hippocampus, amygdala, frontal cortex, have not been completely developed and are susceptible to stressful stimuli. Studies on earthquake experience confirmed that earthquake trauma could increase the risk of diabetes mellitus. Ciocca et al. found that hyperglycemia was more common in patients who developed post-traumatic stress disorder (PTSD) after 2009 L'Aquila in Italy [5]. After the Eastern Japan earthquake on 11th March 2011, a study of 497 diabetic patients showed that blood glucose control was poor in 3 months after the earthquake, which was related to endogenous insulin secretion caused by hyperactivity of sympathetic nerve caused by stress [6]. Our previous study found that the resting heart rate and fasting blood glucose level increased significantly in adults who experienced earthquake stress during their adolescence and childhood [7, 8]. However, there has been no study on the subsequent risk of diabetes in adults who have experienced earthquake in their prenatal life.

On the early morning of July 28,1976 , an earthquake with a magnitude of 7.8 hit Tangshan, Hebei province, China and lasted to $14-16 \mathrm{~s}$ and followed by a major 7.1 magnitude aftershock. Approximately a quarter million people succumbed and 160.000 people suffered from severe injuries. Such catastrophic earthquake could cause extreme stress on pregnant mother and their developing fetuses. In the current cross-sectional study, we sought to determine the prevalence of diabetes mellitus among adults who had experienced the 1976 Tangshan Earthquake in their fetal life.

\section{Subjects and methods}

\section{The study population}

This study included employees of Tangshan Kailuan Mining Group between July 29, 1976 and April 28, 1977. The exposure group included subjects who experienced the
Tangshan Earthquake during their prenatal period and who had lived in Tangshan since birth. The non-exposure group included subjects who did not experience the Tangshan Earthquake during their fetal period and were born 1-1.9 years after the earthquake and who had lived in Tangshan since birth. Exclusion criteria were as follows: 1 ) acute disease or traumatic surgery; 2) severe liver disease; 3) secondary diabetes mellitus (such as pancreatic disease or pancreatectomy, Cushing's syndrome, and thyroid disease, etc.); 4) psychiatric diseases; 5) pregnant women; 6) history of severe stressful life events.

The study protocol was approved by the Ethics Committee of the First Hospital of Hebei Medical University (No 2014005). Informed consents were obtained from all study subjects before enrollment.

\section{Questionnaire}

A questionnaire was designed that included sociodemographic information, conditions during pregnancy, and earthquake experience. Information regarding the earthquake and pregnancy was provided by parents of the study subjects. Demographic information included age, gender, education, marriage, and monthly income. Earthquake experience included mother's condition, infant's birth weight and loss of any family members.

Past history included past physical and mental illness, smoking and drinking. Smoking was defined as a continuous or cumulative smoking for more than 6 months in a lifetime, with at least 1 cigarette per day. Smoking cessation or abstinence: those who met smoking or drinking conditions had been at least 6 months without smoking or drinking at the time of investigation. Alcohol consumption was defined as an average daily alcohol content of $100 \mathrm{~mL}$ (alcohol content was more than 50\%), lasting more than 6 months. Light alcohol consumption was defined as an average monthly alcohol consumption less than 120 standard cups [9]. Heavy alcohol consumption was defined as an average daily alcohol consumption above $50 \mathrm{~mL}$ (about 4 standard cups) or an average monthly alcohol consumption of more than 120 standard cups.

\section{Physical examination}

Height and weight were measured by the corrected RGZ-120 body weight scale. Body weight was measured with light clothes on and shoes and hats taken off. Body mass index (BMI) was calculated as weight divided by height squared $\left(\mathrm{Kg} / \mathrm{m}^{2}\right)$. Waistline measurement was the circumference of the finest position of the waist, with the value was accurate to $0.1 \mathrm{~cm}$. Blood pressure was measured $30 \mathrm{~min}$ after the subject had stopped smoking, drinking tea or coffee. The right arm brachial artery blood pressure was measured by the corrected mercury sphygmomanometer. Three measurements were made at 
an interval of $1-2 \mathrm{~min}$ and the average value was adopted. Hypertension was diagnosed by systolic blood pressure (SBP) $\geq 140 \mathrm{mmHg}$ and/or diastolic blood pressure $(\mathrm{DBP}) \geq 90 \mathrm{mmHg}$, or subjects were taking the antihypertensive medications at the time of the study. Diabetes mellitus was diagnosed if FPG was $>126 \mathrm{mg} / \mathrm{dL}$ $(7.0 \mathrm{mmol} / \mathrm{L})$, or subjects who were taking hypoglycemic drugs or using insulin at the time of the study.

\section{Laboratory study}

Blood samples were collected in $5 \mathrm{~mL}$ EDTA vacuum collection tubes (Inspeck, ST750EK, Sekisui, Osaka, Japan) between 7:00 a.m. and 9:00 a.m.. Blood samples were centrifuged at $3000 \times \mathrm{g}$ for $10 \mathrm{~min}$ at room temperature, and the supernatant was collected for assaying fasting plasma glucose (FPG), triglycerides (TG), low-density lipoprotein cholesterol (LDL-C), total cholesterol (TC), and high-density lipoprotein cholesterol (HDL-C). FPG levels were tested by the hexokinase method (BioSino Bio-Technology \& Science Inc.) TG, LDL-C, HDL-C and TC were measured by the oxidase method (Shanghai Mind Bioengineering Co, Ltd, Shanghai, China). Measurements were performed using a Hitachi 7600 Automatic Biochemical Analyzer.

\section{Statistical analysis}

All data were analyzed using SPSS21.0 (SPSS Inc., Chicago, IL, USA). The exposure group was further divided into the first trimester group for subjects who were (born between January 29, 1977 and April 28, 1977), the second trimester group for subjects who were born between October 29, 1976 and January 28, 1977) and the third trimester group who were born between July 29, 1976 and October 1976. One-way ANOVA was used to compare variables among groups. Kruskal-Wallis test and Student's $t$ test were used for comparison of continuous variables between subjects in the exposed and non-exposed group where appropriate. The comparison of the prevalence of hypertension and diabetes mellitus among groups was performed using the chisquare test. We used multivariate logistic regression analysis in which the incidence of diabetes was used as a dependent variable while hypertension, gender, age, earthquake stress during different gestational periods, BMI, TC, TG, HDL, LDL, family history of diabetes, family loss, smoking and drinking status were used as independent variables. $P<0.05$ was considered statistically significantly different.

\section{Results}

Demographic and baseline characteristic of the study population

Totally 1081 subjects met the inclusion criteria and returned the questionnaires. Nine hundred forty-seven $(87.6 \%)$ of the questionnaires were effective. They included 397 subjects in the exposed group and 550 subjects in the non-exposed group. The demographic and baseline characteristic of the study population are shown in Table 1. The two groups were comparable in demographic and baseline variables $(P>0.05)$ except age $\left(\chi^{2}=\right.$ 411.82, $P<0.01)$.

\section{Anthropometric and metabolic characteristics of the study population}

The anthropometric and metabolic characteristics of the study population are shown in Table 2. The average of SBP in the third trimester group $(123.6 \pm 9.7 \mathrm{mmHg})$ and the second trimester group $(123.5 \pm 11.0 \mathrm{mmHg})$ were higher than that of the non-exposure group $(121.3 \pm 12.4 \mathrm{mmHg})$. The average of FBG in the third trimester group $(5.12 \pm 2.63 \mathrm{mmHg})$, the second trimester group $(5.10 \pm 1.22 \mathrm{mmHg})$ and the first trimester group $(5.20 \pm 1.33 \mathrm{mmHg})$ were higher than that of the non-exposure group $(4.96 \pm 1.35 \mathrm{mmHg})$.

\section{Incidence of diabetes mellitus}

The diabetes rate is significant different in these four groups $\left(\chi^{2}=8.045, P=0.045\right)$. Moreover, 11.8, 7.5 and 8.0\% of the subjects who were exposed to earthquake in the $1 \mathrm{st}$, 2nd, and 3rd trimester of pregnancy had diabetes. $5.1 \%$ of the subjects had diabetes in non-exposure group.

\section{Multivariate analysis of risk factors for diabetes}

Our multivariate analysis showed that 1st trimester (OR 2.481, 95\%CI 1.02,6.034; $P=0.045$ ) and loss of family members during earthquake (OR 2.452, 95\%CI 1.293, 4.653; $P=0.006)$ were associated with significantly increased risk of diabetes. In addition, higher BMI (OR 1.113, 95\%CI 1.004,1.233; $P=0.042$ ), higher TG levels (OR 1.194, 95\%CI 1.045,1.364; $P=0.009$ ) were independent risk factors for diabetes. Meanwhile, light alcohol consumption (OR 0.181, 95\%CI 0.055,0.597; $P=0.005$ ) was associated with reduced risk of diabetes (Table 3 ).

\section{Discussion}

Our study found that exposure to earthquake during the first trimester of pregnancy and experience of family member loss in the earthquake significantly increased the subsequent risk of diabetes in the middle age (36-39 years of age). Our data suggest that earthquake experience in the early pregnancy has a longer-term effect on diabetes risk during adulthood.

Previous studies have shown that maternal mental distress during the critical period of fetal development could impact on the neuroendocrine function of offspring $[4,10]$. Animal experiments also confirmed that maternal stressful events during pregnancy had significant effects on behavioral and metabolic phenotypes in the adult offspring of rats $[11,12]$. Mental trauma could 
Table 1 Sociodemographic characteristics of the study population

\begin{tabular}{|c|c|c|c|c|c|c|}
\hline & \multicolumn{3}{|c|}{ Exposure to earthquake } & \multirow[t]{2}{*}{ Non-exposure to earthquake } & \multirow[t]{2}{*}{$x^{2}$} & \multirow[t]{2}{*}{$P$} \\
\hline & 3rd trimester & 2nd trimester & 1st trimester & & & \\
\hline $\mathrm{N}$ & 137 & 133 & 127 & 550 & & \\
\hline Male gender, n(\%) & $125(91.2)$ & $116(87.2)$ & $107(84.3)$ & $476(86.5)$ & 3.135 & 0.375 \\
\hline Ethnicity, n(\%) & & & & & 1.208 & 0.751 \\
\hline Han & $136(99.3)$ & $130(97.7)$ & $125(98.4)$ & $539(98.0)$ & & \\
\hline Minorities & $1(0.7)$ & $3(2.3)$ & $2(1.6)$ & $11(2.0)$ & & \\
\hline Educational level, n(\%) & & & & & 8.628 & 0.196 \\
\hline$<6$ years & $3(2.2)$ & $3(2.3)$ & $2(1.6)$ & $6(1.1)$ & & \\
\hline $6-12$ years & $103(75.7)$ & $94(70.7)$ & $87(69.6)$ & $361(65.6)$ & & \\
\hline$>12$ years & $30(22.1)$ & $36(27.1)$ & $36(28.8)$ & $183(33.3)$ & & \\
\hline Mean age, years & $39.0 \pm 0.2$ & $38.7 \pm 0.5$ & $38 \pm 0.3$ & $37.5 \pm 0.6$ & 411.82 & $<0.0001$ \\
\hline Marital status & & & & & 4.147 & 0.657 \\
\hline Not married & $3(2.2)$ & $2(1.5)$ & $2(1.6)$ & $3(0.5)$ & & \\
\hline Married & $126(93.6)$ & $125(94)$ & $119(93.7)$ & $515(93.6)$ & & \\
\hline Divorce, remarriage and widowhood & $8(5.8)$ & $6(4.5)$ & $6(4.7)$ & $32(5.8)$ & & \\
\hline Occupation, n(\%) & & & & & 1.810 & 0.575 \\
\hline Manual labor & $111(84.7)$ & $112(87.5)$ & $101(82.1)$ & $438(82.2)$ & & \\
\hline Others & $26(15.3)$ & $21(12.5)$ & $25(17.9)$ & $115(17.8)$ & & \\
\hline Smoking history, n(\%) & & & & & 3.413 & 0.756 \\
\hline Smoker & $68(49.6)$ & $65(49.2)$ & $61(48.8)$ & $277(50.9)$ & & \\
\hline Former smoker & $15(10.9)$ & $10(7.6)$ & $8(6.4)$ & $54(9.9)$ & & \\
\hline Non-smoker & $54(39.4)$ & $57(43.2)$ & $56(44.8)$ & $213(39.2)$ & & \\
\hline Drinking, $n(\%)$ & & & & & 4.008 & 0.261 \\
\hline No drinking & $36(26.3)$ & $45(33.8)$ & $40(31.5)$ & $150(27.3)$ & & \\
\hline Light drinking & $84(61.3)$ & $77(57.9)$ & $81(63.8)$ & $369(67.1)$ & & \\
\hline Heavy drinking & $17(12.4)$ & $11(8.3)$ & $6(4.7)$ & $31(5.6)$ & & \\
\hline Family loss in the earthquake, $n(\%)$ & $65(47.4)$ & $62(46.6)$ & $247(44.9)$ & $55(43.3)$ & 0.585 & 0.900 \\
\hline Diabetes mellitus, $\mathrm{n}(\%)$ & $11(8.0)$ & $10(7.5)$ & $15(11.8)$ & $28(5.1)$ & 8.045 & 0.045 \\
\hline
\end{tabular}

Table 2 Anthropometric and metabolic characteristics of the study population (mean \pm SD) or median(P25, P75)

\begin{tabular}{|c|c|c|c|c|}
\hline & Exposure to e & & No exposure & \\
\hline & 3rd trimester & 2nd trimester & 1st trimester & \\
\hline $\mathrm{N}$ & 137 & 133 & 127 & \\
\hline BMI $\left(\mathrm{kg} / \mathrm{m}^{2}\right)$ & $25.55 \pm 3.14$ & $24.82 \pm 2.84$ & $24.88 \pm 3.10$ & $25.11 \pm 3.16$ \\
\hline $\mathrm{SBP}(\mathrm{mmHg})$ & $123.6 \pm 9.7$ & $123.5 \pm 11.0$ & $121.9 \pm 10.6$ & $121.3 \pm 12.4$ \\
\hline $\mathrm{DBP}(\mathrm{mmHg})$ & $81.7 \pm 8.4$ & $81.1 \pm 8.9$ & $81.1 \pm 7.3$ & $83.2 \pm 9.4$ \\
\hline FPG (mmol/L) & $5.12 \pm 2.63$ & $5.10 \pm 1.22$ & $5.20 \pm 1.33$ & $4.96 \pm 1.35$ \\
\hline $\mathrm{TC}(\mathrm{mmol} / \mathrm{L})$ & $5.26 \pm 1.15$ & $5.20 \pm 0.98$ & $5.06 \pm 0.96$ & $5.09 \pm 1.09$ \\
\hline TG $(\mathrm{mmol} / \mathrm{L})$ & $3.0(1.5,5.6)$ & $2.1(1.1,2.8)$ & $1.5(0.8,2.9)$ & $2.2(1.2,3.3)$ \\
\hline $\mathrm{HDL}(\mathrm{mmol} / \mathrm{L})$ & $1.62 \pm 0.31$ & $1.67 \pm 0.35$ & $1.63 \pm 0.36$ & $1.64 \pm 0.34$ \\
\hline LDL (mmol/L) & $2.80 \pm 0.74$ & $2.87 \pm 0.72$ & $2.83 \pm 0.67$ & $2.84 \pm 0.76$ \\
\hline
\end{tabular}


Table 3 Multivariate logistic regression analysis of risk factors of diabetes mellitus

\begin{tabular}{|c|c|c|c|c|c|c|}
\hline & B & S.E & Walds & $P$ & OR & $95 \% \mathrm{Cl}$ \\
\hline Hypertension & -0.132 & 0.383 & 0.118 & 0.731 & 0.877 & $(0.414,1.858)$ \\
\hline Gender & -1.509 & 0.792 & 3.634 & 0.057 & 0.221 & $(0.047,1.043)$ \\
\hline Age & 0.149 & 0.348 & 0.184 & 0.668 & 1.161 & $(0.587,2.296)$ \\
\hline BMI & 0.107 & 0.053 & 4.122 & 0.042 & 1.113 & $(1.004,1.233)$ \\
\hline $\mathrm{TC}$ & -0.011 & 0.201 & 0.003 & 0.958 & 0.99 & $(0.667,1.467)$ \\
\hline TG & 0.177 & 0.068 & 6.817 & 0.009 & 1.194 & $(1.045,1.364)$ \\
\hline $\mathrm{HDL}$ & 0.375 & 0.478 & 0.615 & 0.433 & 1.455 & $(0.57,3.716)$ \\
\hline LDL & 0.391 & 0.224 & 3.062 & 0.08 & 1.479 & $(0.954,2.293)$ \\
\hline Sub-groups & & & 4.974 & 0.174 & & \\
\hline 3rd trimester & 0.893 & 0.623 & 2.056 & 0.152 & 2.443 & $(0.72,8.281)$ \\
\hline 2nd trimester & 1.03 & 0.574 & 3.215 & 0.073 & 2.8 & $(0.909,8.63)$ \\
\hline 1st trimester & 0.909 & 0.453 & 4.014 & 0.045 & 2.481 & $(1.02,6.034)$ \\
\hline Family history of diabetes & 0.626 & 0.458 & 1.866 & 0.172 & 1.869 & $(0.762,4.587)$ \\
\hline Family loss & 0.897 & 0.327 & 7.537 & 0.006 & 2.452 & $(1.293,4.653)$ \\
\hline \multicolumn{7}{|l|}{ Smoking status } \\
\hline Non- smoker & & & 3.165 & 0.205 & & \\
\hline Light smoker & 0.499 & 0.363 & 1.892 & 0.169 & 1.647 & $(0.809,3.352)$ \\
\hline Heavy smoker & 0.886 & 0.538 & 2.714 & 0.1 & 2.425 & $(0.845,6.959)$ \\
\hline \multicolumn{7}{|l|}{ Drinking status } \\
\hline Non-drinker & & & 13.455 & 0.004 & & \\
\hline Light drinker & -1.715 & 0.54 & 10.097 & 0.005 & 0.181 & $(0.055,0.597)$ \\
\hline Heavy drinker & 1.101 & 0.583 & 3.568 & 0.059 & 3.007 & $(0.959,9.426)$ \\
\hline Constant & -12.379 & 13.088 & 0.895 & 0.344 & 0 & \\
\hline
\end{tabular}

Note. BMI body mass index, TC total cholesterol, TG triglyceride, HDL high density lipoprotein, $L D L$ low density lipoprotein

lead to increased blood glucose, which is mainly due to the maladaptive pattern of stress-related hormones. The HPA axis would become overactive and release excessive amounts of cortisol and other hormones when an individual is exposed to traumatic events [13, 14], which could lead to obesity, massive visceral fat accumulation, dyslipidemia and increased insulin resistance [15]. On the other hand, increased glucocorticoid during pregnancy might change the responsiveness toward stress and reduces the expression of $11 \beta$-hydroxysteroid dehydrogenase, and finally increase anxiety like behaviors and decrease neurodevelopment of offspring. This could increase vulnerability to hypertension, dyslipidemia, hyperglycemia and metabolic-related diseases of middleaged persons [16]. In the present study, women suffered from severe earthquake trauma during pregnancy, suggesting that dramatic changes in the internal environment could give rise to sympathetic hyperfunction, which plays an important role in intrauterine vasoconstriction and fetal hypoxia. Meanwhile, the excessive release of stress-related hormones from the maternal body to the fetus via the placenta could lead to an increased risk of compromised fetal development and metabolic abnormalities.

A large epidemiological survey of 408,015 Dutch men born in 1944-1947 confirmed that there was a significant correlation between famine exposure in the first trimester of pregnancy and the long-term mortality of offspring, suggesting that early-life stressful events influenced the outcome of chronic diseases [17]. This is in line with the results of our research. The first trimester of pregnancy is a critical period for the formation of the fetal organs, which is very sensitive to the stimulation of the internal and external environment during this period. At this time, stress could substantially increase the subsequent risk of somatic disease.

A study of maternal exposure to the famine in Holland found that with an increase of blood glucose levels by $0.3 \mathrm{mmol} / \mathrm{L}$, the mean waist circumference increased by $3 \mathrm{~cm}$, and the risk of obesity (BMI $>25 \mathrm{~kg} / \mathrm{m}^{2}$ ) increased significantly. In our study, the level of FPG increased by $0.3 \mathrm{mmol} / \mathrm{L}$ in the early stage of pregnancy than in the non-exposure group [16]. Our study did not find a significant correlation on mid-age BMI and maternal 
exposure to earthquake, which might be due to different stressors, and our subjects were all coal miners who mostly engaged in heavy physical labor.

Our present study found that the loss of relatives increased the risk of long-term diabetes in the first trimester. Previous studies found that after experiencing major life events such as death of the eldest son or a loved one, the subsequent risk of type 2 diabetes increased significantly [18]. Other surveys found that the prevalence of diabetes increased significantly in the offspring of pregnant women when their mothers passed away from their loved ones or family members. The sudden loss of kinship caused by the earthquake, especially the loss of first-degree relatives, could significantly increase the stress caused by the earthquake itself, increase the intensity and duration of stress of pregnant women, thereby directly and indirectly affecting the development of the fetus and increasing the risk of metabolic diseases of the offspring.

Our study didn't find a correlation between smoking and heavy drinking and the development of diabetes, while light alcohol consumption was a protective factor for diabetes. Wakabayashi et al. investigated 12,627 middle-aged Japanese men and explored the risk of alcohol consumption on diabetes. Compared with nondrinkers, light-to-moderate alcohol consumption $(<22 \mathrm{~g} /$ day) could significantly reduce the risk of diabetes, while extremely heavy drinking ( $>44 \mathrm{~g} /$ day) had no significant impact on diabetes [19]. A meta-analysis, which included 13 prospective studies, showed that alcohol consumption (g/day) was associated with the prevalence of diabetes into the U-curve, and that drinking alcohol or beer per day for $20-30 \mathrm{~g} /$ days was the lowest in diabetes. This is basically the same as our research results [14].

There were some limitations in our present study. Given the cross-sectional design and relatively small female sample cohort of the study, it was relatively less representative. A further follow-up was required to clarify the influence of earthquake stress on psychosomatic diseases. In addition, there were many confounding factors in psychosomatic disease, such as diet habits, lifestyle and family status (e.g. single-parent family, economic status, and parenting style, etc.); the above factors, however, are difficult to quantify at present. Moreover, our study will further explore the mechanism of prenatal stress and psychosomatic diseases through gene polymorphism, DNA methylation and multimodal fMRI.

In conclusion, experience of earthquake during the first trimester of the fetal life and loss of family member loss in the earthquake significantly increased the subsequent risk of diabetes in the adulthood, suggesting that earthquake experience in the early pregnancy has a longer-term effect on diabetes risk.

\section{Abbreviations}

BMl: Body mass index; FPG: Fasting plasma glucose; HPA: Hypothalamuspituitary-adrenal; PTSD: Post-traumatic stress disorder; SBP: Systolic blood pressure; DBP: Diastolic blood pressure; TG: Triglycerides; LDL-C: Low-density lipoprotein cholesterol; TC: Total cholesterol; HDL-C: High-density lipoprotein cholesterol

\section{Acknowledgements \\ None. \\ Authors' contributions \\ $\mathrm{Na}$ Li, Cui-Xia An and Xue-Yi Wang contributed to the conception and de- sign of the study; Mei Song, Lan Wang, Xiao-chuan Zhao, Ran Wang, Yuan- yuan Gao and Lu-lu Yu performed the experiments, collected and analyzed data; Na Li, Cui-Xia An and Xue-Yi Wang wrote the manuscript; All authors reviewed and approved the final version of the manuscript.}

\section{Funding}

This work was supported by research grants from National Science Foundation of China (No. 81271489), Hebei Province Natural Science Foundation of China (No.H20142062) and Government-funded Program for Training Excellent Clinical Medical Talents and Fundamental Research (LS201612).

\section{Availability of data and materials}

The datasets generated and analyzed during the current study are available from the corresponding author on reasonable request.

\section{Ethics approval and consent to participate}

The study protocol was approved by the Ethics Committee of the First Hospital of Hebei Medical University. Informed consent was obtained from all the study subjects before enrollment.

\section{Consent for publication}

Not applicable.

\section{Competing interests}

The authors declare that they have no competing interests.

Received: 27 May 2020 Accepted: 26 October 2020

Published online: 10 November 2020

\section{References}

1. Entringer S, Epel ES, Kumsta R, Lin J, Hellhammer DH, Blackburn EH, et al. Stress exposure in intrauterine life is associated with shorter telomere length in young adulthood. Proc Natl Acad Sci U S A. 2011;108(33):E513-8.

2. Fu J, Li XJ, Zhu HL, Song Y, Yang SY, Tan J, et al. Pregnant Outcomes of Multiparae in Women with Advanced Age (>/=35 years) after the 2008 Wenchuan Earthquake. Sichuan Da Xue Xue Bao Yi Xue Ban. 2017:48(5): 736-9.

3. Entringer S, Buss C, Wadhwa PD. Prenatal stress and developmental programming of human health and disease risk: concepts and integration of empirical findings. Curr Opin Endocrinol Diabetes Obes. 2010;17(6):507-16.

4. Sotomayor O. Fetal and infant origins of diabetes and ill health: evidence from Puerto Rico's 1928 and 1932 hurricanes. Econ Hum Biol. 2013;11(3): 281-93.

5. Ciocca G, Carosa E, Stornelli M, Limoncin E, Gravina GL, lannarelli R, et al. Post-traumatic stress disorder, coping strategies and type 2 diabetes: psychometric assessment after L'Aquila earthquake. Acta Diabetol. 2015; 52(3):513-21.

6. Fujihara K, Saito A, Heianza Y, Gibo H, Suzuki H, Shimano H, et al. Impact of psychological stress caused by the great East Japan earthquake on glycemic control in patients with diabetes. Exp Clin Endocrinol Diabetes. 2012;120(9): 560-3.

7. $\quad$ Li N, Wang Y, Yu L, Song M, Wang L, Ji C, et al. Long-term effects of earthquake experience of young persons on cardiovascular disease risk factors. Arch Med Sci. 2017:13(1):75-81.

8. An C, Zhang Y, Yu L, Li N, Song M, Wang L, et al. Long-term impact of earthquake stress on fasting glucose control and diabetes prevalence among Chinese adults of Tangshan. Int J Clin Exp Med. 2014;7(11):4441-7.

9. Hao W. Guidelines for the diagnosis and treatment of alcohol related disorders; 2014. p. 7. 
10. Virk J, Li J, Vestergaard M, Obel C, Lu M, Olsen J. Early life disease programming during the preconception and prenatal period: making the link between stressful life events and type-1 diabetes. PLoS One. 2010;5(7): e11523.

11. Maccari S, Darnaudery M, Morley-Fletcher S, Zuena AR, Cinque C, Van Reeth $O$. Prenatal stress and long-term consequences: implications of glucocorticoid hormones. Neurosci Biobehav Rev. 2003;27(1-2):119-27.

12. Weinstock $M$. The potential influence of maternal stress hormones on development and mental health of the offspring. Brain Behav Immun. 2005; 19(4):296-308

13. Tataranni PA, Larson DE, Snitker S, Young JB, Flatt JP, Ravussin E. Effects of glucocorticoids on energy metabolism and food intake in humans. Am J Phys. 1996;271(2 Pt 1):E317-25.

14. Huang J, Wang $X$, Zhang $Y$. Specific types of alcoholic beverage consumption and risk of type 2 diabetes: a systematic review and metaanalysis. J Diabetes Investig. 2017;8(1):56-68.

15. Bjorntorp P. Do stress reactions cause abdominal obesity and comorbidities? Obes Rev. 2001;2(2):73-86.

16. Hult M, Tornhammar P, Ueda P, Chima C, Bonamy AK, Ozumba B, et al. Hypertension, diabetes and overweight: looming legacies of the Biafran famine. PLoS One. 2010;5(10):e13582.

17. Ekamper P, van Poppel F, Stein AD, Lumey LH. Independent and additive association of prenatal famine exposure and intermediary life conditions with adult mortality between age 18-63 years. Soc Sci Med. 2014;119:232-9.

18. Mooy JM, de Vries H, Grootenhuis PA, Bouter LM, Heine RJ. Major stressful life events in relation to prevalence of undetected type 2 diabetes: the Hoorn study. Diabetes Care. 2000;23(2):197-201.

19. Wakabayashi I. Light-to-moderate alcohol drinking reduces the impact of obesity on the risk of diabetes mellitus. J Stud Alcohol Drugs. 2014;75(6): 1032-8.

\section{Publisher's Note}

Springer Nature remains neutral with regard to jurisdictional claims in published maps and institutional affiliations.

Ready to submit your research? Choose BMC and benefit from:

- fast, convenient online submission

- thorough peer review by experienced researchers in your field

- rapid publication on acceptance

- support for research data, including large and complex data types

- gold Open Access which fosters wider collaboration and increased citations

- maximum visibility for your research: over $100 \mathrm{M}$ website views per year

At $\mathrm{BMC}$, research is always in progress.

Learn more biomedcentral.com/submissions 